\title{
Yeast derived Fe-doped Hollow Carbon as a Superior Sulfur Host for Li-S Batteries
}

\author{
Yifan Zheng, Wangjun Feng *
}

School of Science, Lanzhou University of Technology, Lanzhou 730050, China

*E-mail: wjfeng@lut.cn

doi: $10.20964 / 2021.03 .51$

Received: 23 November 2020 / Accepted: 13 January 2021 / Published: 31 January 2021

To overcome the charging and discharging problems of lithium sulfur batteries due to their shuttle effect, low conductivity, and volume expansion, researchers have proposed many solutions. Here, we designed an S@Fe-CY electrode in which yeast is carbonized at high temperatures to preserve its porous morphology, and then it is doped with Fe to enhance its electrochemical performance. The electrochemical test proved that S-@Fe-CY has excellent multiplication performance and cyclic stability. The initial discharge capacity of the lithium-sulfur battery with S@Fe-CY as the electrode material was $985.3 \mathrm{mAh} / \mathrm{g}$ at $0.2 \mathrm{C}$, which showed an improvement in electrochemical performance characteristics.

Keywords: Lithium-sulfur battery; porous carbon; thermal treatment

\section{FULL TEXT}

(C) 2021 The Authors. Published by ESG (www.electrochemsci.org). This article is an open access article distributed under the terms and conditions of the Creative Commons Attribution license (http://creativecommons.org/licenses/by/4.0/). 